\title{
Ethnic discrimination in secondary education: Does the solution lie in multicultural education and the ethnic school composition?
}

\author{
Fanny $D^{\prime}$ hondt $^{1}$ (D) Charlotte Maene ${ }^{1}$ (D) Roselien Vervaet $^{1}$ (D) \\ Mieke Van Houtte $^{1}$ (D) Peter A. J. Stevens ${ }^{1}$ (D)
}

Received: 10 December 2020 / Accepted: 20 July 2021 / Published online: 16 August 2021

(c) The Author(s) 2021

\begin{abstract}
Ethnic discrimination is a serious problem in education. Previous quantitative research is predominately focused on the consequences of ethnic discrimination. Very little is known, however, about the characteristics of the school context that influence the initial experience of ethnic discrimination. This knowledge is essential to support schools in how to organize in a way that diminishes the likelihood of adolescents being discriminated against. This study examines the relationship between multicultural education and perceived ethnic discrimination, and the moderating role of the ethnic composition of the student population. Multicultural education is a broad concept. The focus lies on the three main actors: multicultural policy from the perspective of the principal, multicultural teaching from the perception of the teacher and students' perception of multicultural teaching. The results of a multilevel analysis on a large-scale dataset $(\mathrm{N}=2715$ students, 38 schools) collected in secondary education in Belgium show that students of ethnic Belgian descent are more likely to report ethnic discrimination by peers if the school applies a more multicultural policy or if the school has a high concentration of students with an other-than-Belgian background. Students with an other-than-Belgian background are more likely to report ethnic discrimination by teachers if the school applies a more multicultural policy. If students perceive that their teachers pay attention to multicultural education, they are less likely to report ethnic discrimination by teachers, but more by peers. The ethnic composition is not directly related to perceived ethnic discrimination, nor does it play a moderating role.
\end{abstract}

Keywords Ethnic discrimination · Multicultural education $\cdot$ Ethnic school composition $\cdot$ Secondary education

Fanny D'hondt

fanny.dhondt@ugent.be

1 CESSMIR and CuDOS, Department of Sociology, Ghent University, Ghent, Belgium 


\section{Introduction}

Ethnic discrimination is a serious problem in different domains of society (Hebl et al., 2020; Pager \& Shepherd, 2008; Williams et al., 2019), including education (Fisher et al., 2000; Stevens \& Dworkin, 2019). Previous research has focused predominantly on the consequences of ethnic discrimination. Very little is known, however, about the characteristics of the school context that influence the initial experience of ethnic discrimination (Benner \& Graham, 2013; Brown \& Chu, 2012). This knowledge can provide crucial support to schools for instituting organizational and structural changes to decrease the likelihood of adolescents being discriminated against.

There are a few studies that focus on the influence of multicultural education on discrimination. The aim of multicultural education is to organise schools in such a way that students from diverse ethnic groups experience educational equality (Banks, 1993). The existing studies are so limited in number and focus on different actors (i.e., principal, teacher, student), different elements (e.g., school culture, school policy, school brochure) and age groups (from children until college students), that no clear patterns emerge from the results (Apfelbaum et al., 2010; Bellmore et al., 2012; Brown \& Chu, 2012; Verkuyten \& Thijs, 2002b; Wilton, et al. 2015). The relationship between multicultural education and discrimination is complex and multifaceted and the results are often contradictory. Furthermore, there is a clear lack of European studies, despite their importance: the understanding of multicultural education in Europe is different from the United States, as other ethnic minority groups are the focal point (Agirdag et al., 2016).

Next to the role of multicultural education, we focus on its interaction with the ethnic composition of the student population. The ethnic composition of the student population is in itself an important contextual variable in relationship to the experience of ethnic discrimination: literature shows that how the student population is composed (e.g., the ratio between ethnic majority and minority students) can influence the chances of experiencing ethnic discrimination, but the results are inconclusive (Benner \& Graham, 2013; Graham, 2018; Thijs \& Verkuyten, 2014). The ethnic composition of the student population could also be an important variable in gaining a better understanding of the relationship between multicultural education and ethnic discrimination: research shows that teachers tend to pay more attention to multicultural education if more ethnic minority students are present (Agirdag et al., 2016), and as suggested by Thijs and Verkuyten (2014), ethnic composition could be an important condition for the effectiveness of multicultural education. For example, students' reception of the multicultural message may depend on the ethnic school composition (e.g., a diverse student population can make the message seem more relevant).

In order to develop a better understanding of how these two school characteristics influence the experience of ethnic discrimination, this study focuses on multicultural education, the ethnic composition of the student population and the interaction between both. Multicultural education can be related to every element and actor within an educational setting (Banks, 1993; Zembylas \& Iasonos, 2010). 
This study chooses to focus on the three main actors: multicultural policy from the perception of the principal, multicultural teaching from the perception of the teacher and students' perception of multicultural teaching. We take both students with and without a migration background into account to be able to verify these relationships for the whole student population. Moreover, we differentiate (where possible) between perceived discrimination by peers and by teachers to gain real insight into the dynamics that are at play within the walls of a school. These foci combined with an empirical study in a European context (Flanders, Belgium) help to build unique knowledge about how schools can address this detrimental experience.

Flanders is an interesting case. On the one hand because the ethnic educational inequality is high compared to the OECD average according to the PISA studies (De Meyer et al., 2018; OECD, 2016, 2019). On the other hand, because schools are free to choose if and how they implement multicultural education. They only have to fulfill a few broadly defined educational attainment goals (e.g., Students have to have conceptual knowledge about multiculturalism, monoculturalism, integration, assimilation, inclusion, exclusion), which are related to learning goals for the students, not about how to address intercultural relationships or how to organize a school in a way that educational equality is achieved (Flemish Ministry of Education and Formation, 2020). In addition, Flemish teachers also have a lot of autonomy in their classroom. They have to achieve the educational attainment goals, but what and how they teach and even how they evaluate, is their decision.

\section{Background}

\subsection{Ethnic discrimination}

Ethnic discrimination can be defined as the differential treatment on the basis of ethnicity that disadvantages (a member of) an ethnic group (Quillian, 1995). If people hold an ethnic prejudice and they have the power to influence others' experiences and life chances, we speak of ethnic discrimination (Gillborn, 2003). However, this power is unequally distributed in society, so although ethnic discrimination encompasses every form of unequal treatment due of one's ethnic background, most of the ethnic discrimination will be directed from those in society who are more powerful towards those with less power.

A confrontation with ethnic discrimination by teachers and peers in school has a negative impact on a wide range of outcomes, such as adolescents' sense of school belonging, self-esteem, depressive symptoms and grades (Benner et al., 2018; D'hondt et al., 2015; Wong et al., 2003). It affects both the emotional and academic well-being and the achievement of adolescents. The literature on the consequences of ethnic discrimination does not often differentiate between different perpetrators, although the limited evidence shows that it matters (Benner et al., 2018). Discrimination by teachers would have more effect on educational outcomes, while discrimination by peers is more related to socioemotional distress and risky behaviours. The same is true for the link between multicultural education and discrimination. The 
limited evidence shows that it is valuable and necessary to focus on different kinds of discrimination (e.g., peer versus teacher, personal versus group) as not every element of multicultural education is related in the same manner to different kinds of discrimination (Brown \& Chu, 2012; Verkuyten \& Thijs, 2002b).

\subsection{Multicultural education and ethnic discrimination}

The field of multicultural education encompasses a wide range of different definitions, philosophical nuances and school practices. Bennett (1990) defines multicultural education as: 'a democratic approach to teaching and learning that seeks to foster cultural pluralism within culturally diverse societies and an interdependent world. It consists of four distinct but overlapping dimensions: (a) the movement toward educational equity; (b) the curriculum approach that integrates multicultural and global perspectives into the traditional (primarily monoethnic) curriculum; (c) the process of becoming multicultural; and (d) the commitment to combat racism, prejudice, and discrimination'. There are two elements in this definition that we want to highlight. First, the commitment to combat discrimination is an explicit and important pillar of multicultural education; and, as mentioned, the dimensions are overlapping, which means, for example, a teacher or student who is more multiculturally competent will also be less likely to discriminate. Second, the concepts 'movement', 'process of becoming', 'the commitment to', all indicate that multicultural education is not an all-or-nothing approach, but a gradual approach. While some schools might be occupied with just 'managing' the diversity in their school, others can already implement more transformative actions (Zembylas \& Iasonos, 2010). Underlying these four dimensions is a whole range of mechanisms that focus on the knowledge, beliefs, attitudes and skills of teachers and students, on school and classroom climates, on teaching strategies, and so on (Bennett, 2001). As multicultural education is interpreted as a comprehensive approach, it is sometimes difficult to grasp the specific mechanisms that make it successful. Acknowledging cultural differences, fostering intercultural interaction, improving cultural knowledge and dialogue, teaching about tolerance are all elements that help to enhance the mutual understanding of differences and acceptance and to create a positive school climate (Verkuyten \& Thijs, 2013).

The positive consequences of multicultural education have been demonstrated in many empirical studies. It is successful in lowering ethnic prejudice of ethnic majority members (Verkuyten \& Thijs, 2013; Vervaet et al., 2018b) and it enhances the tolerance among different religious groups (Al Sadi \& Basit, 2012). Multiculturalism positively affects inclusive teaching practices, intergroup perspective-taking or feelings of acceptance by ethnic minorities (Aragón et al., 2017; Meeussen et al., 2014; Todd \& Galinsky, 2012).

Explicitly in relationship with ethnic discrimination, we see similar positive results, however, it depends on which aspects of multicultural education and discrimination are taken into account. An American study focusing on high school students showed that school norms promoting ethnic and cultural diversity were associated with perceiving less peer discrimination (Bellmore et al., 2012). A study 
focusing on Mexican immigrant children in the United States shows that Mexican immigrant children perceived less peer discrimination when their teachers valued diversity, however, no effect for teacher discrimination was found (Brown \& Chu, 2012). Furthermore, the school multicultural policy did not result in any significant impact on the perceived peer or teacher discrimination. An American study let university students review a college brochure with a diversity statement and found that a multicultural diversity statement was related with fewer expectations-across all race groups — of encountering bias at this university (Wilton et al., 2015).

However, multiculturalism also seems to influence the vigilance of students. In this field of study, the central focus is on perceived ethnic discrimination, rather than on the number of incidents. As a consequence, these studies capture an intertwinement between the incidents an individual experiences and the attribution process to interpret a situation as being ethnically discriminatory (Major et al., 2002). An interesting study in this regard is the experimental study of Apfelbaum and colleagues (2010) that shows that children who were exposed to a story of a teacher who valued diversity were more likely to label both ambiguous and explicit incidents of ethnic discrimination as such. A similar result was found by Verkuyten and Thijs (2002a). More multicultural education from the shared perspective of the pupils was related with more reports of peers being discriminated, specifically among Turkish-Dutch children (immigrant descent) and Dutch children (non-immigrant descent); likewise, for Dutch children this was also related with more reports of personal discrimination. For the other children with an immigrant background, this had no effect. However, this study also finds that teachers' assessment of the level of multicultural education is related with lower levels of pupil-reported peer-discrimination, but not with pupils' personal experiences of discrimination. Hence, multicultural education is not only about lowering the number of incidents of ethnic discrimination, but might also be about sensitizing individuals to recognize ambiguous and explicit situations of ethnic discrimination. It might help to provide language to label a negative situation as being discriminatory and raise an individual's awareness.

These empirical studies show that the relationship between multicultural education and ethnic discrimination is complex and that more research is needed. To structure all these different takes on multicultural education, we start from the three central actors in schools: principals, teachers and students. First, principals play a central role in setting the stage for a multicultural school environment. They do not have the interpersonal contact with students as teachers do, but their decisions set the tone for the school environment. They can, for instance, directly influence the welcoming climate of the school (Khalifa et al., 2016). Second, teachers are important authority figures for adolescents (Gregory \& Ripski, 2008; Patrick et al., 2001). Adolescents spend several hours a day listening to and interacting with their teachers. The multicultural messages that teachers bring play an important role in shaping adolescents. Within European multicultural teaching, there is a strong focus on the implementation of various ethnical viewpoints and diverse examples into the traditional school curriculum (Geerlings et al., 2019). Theoretically, this corresponds with Banks' (1993) 'content integration' dimension (Agirdag et al., 2016), and so far, this is the most widely implemented aspect of multicultural teaching in Flanders (Vervaet et al., 2018b). Other research shows that teachers often combine content 
integration with promoting positive views on cultural diversity and intergroup relations, more specifically by conveying the message that discrimination is unacceptable (Verkuyten \& Thijs, 2013). Furthermore, it is not only about the qualitative interpretation of multicultural teaching, but also about the quantity. As the system shifts from primary to secondary education, students have contact with different teachers for different subjects. Hence, as not all lessons lend themselves easily to be culturally responsive and not all teachers are well-trained or equipped to deal with cultural diversity, not every student will be equally submerged in multicultural teaching (Banks, 1993). Therefore, it is important to also take students' perceptions of multicultural teaching into account (Verkuyten \& Thijs, 2002b; Vervaet et al., 2018 b). In so doing, we allow for the possibility to investigate how students' lived experiences of multicultural teaching are related with ethnic discrimination. In line with the Thomas Theorem (Thomas \& Thomas, 1928), 'If people define situations as real, they become real in their consequences', it is theoretically interesting to test the relationship between students' experiences of discrimination and their interpretations of teachers' efforts to focus on multiculturalism during their lessons.

\subsection{Ethnic composition and ethnic discrimination}

In an educational context, a different power dynamic might be at play than in wider society. The student population in a school can vary from no students with an immigrant background to only students with an immigrant background. Due to changing demographics in schools, the numerical majority does not always overlap with the students who are considered ethnically dominant students in the wider society (Graham, 2006; Juvonen et al., 2006). This idea of power in numbers is central to the imbalance of power thesis (Graham, 2006; Juvonen et al., 2006). An individual student is more likely to experience ethnic discrimination by peers when she/he is in a numerical minority position in school. This implies that for students who belong to the dominant ethnic group in society, the presence of more ethnic minority students will raise their chances of being discriminated against, while for students with an immigrant background the opposite is true (Bellmore et al., 2012; Juvonen et al., 2018; Maykel Verkuyten \& Thijs, 2002a, 2002b). However, there are also studies that find no evidence of discrimination (Vervoort et al., 2010), or only evidence for students with an immigrant background (Agirdag et al., 2011). One explanation for these deviating results is that the power dynamics that exist in the wider society are more decisive than the power dynamics that exist within a school. Holding a dominant position in society gives one the power to discriminate, regardless of the exact numerical position.

\subsection{Multicultural education, ethnic composition and ethnic discrimination}

Next to the direct role that multicultural education and ethnic composition might play in the experience of ethnic discrimination, it is plausible to expect that the ethnic composition of the student population will interact with multicultural education. Flemish research in primary schools shows that teachers tend to pay more attention 
to multicultural teaching in schools with higher proportions of ethnic minority pupils (Agirdag et al., 2016), but we have little knowledge about how this ethnic context could moderate the relationship between multicultural education and the experience of ethnic discrimination. As the ethnic composition influences the opportunity to come into contact with students of different ethnic backgrounds, it will influence how central diversity is in the lives of the adolescents and it will influence the firsthand knowledge and ideas that students build about ethnic groups (Pettigrew, 1998; Thijs \& Verkuyten, 2014). These are all elements that will have a potential impact on the reception of multicultural education. For example, is the multicultural message in line with the personal experiences of the student or does it contradict with these experiences? We found little empirical evidence, but Brown and Chu (2012) found that in schools with more same-ethnicity students, the students perceived less community discrimination if the school valued diversity highly. However, this was not the case for peer or teacher discrimination.

\subsection{Present study and research questions}

The aim of the current study is to gain insight in how the multicultural approach from the perception of three different actors in school (i.e., principal, teacher, student) and the ethnic composition of the student body is related with the perceived ethnic discrimination for native-Belgian students and students with a migration background. As the relationship of teachers with students differs from that of students with their peers, we differentiate (where possible) between ethnic discrimination by teachers and ethnic discrimination by peers. Furthermore, we examine whether and how the relationship between multicultural education and ethnic discrimination differs according to the ethnic composition. Given the inconclusive findings in the existing literature, our analyses will focus on three main research questions:

Q1 How is multicultural policy from the perception of the principal, multicultural teaching from the perception of the teachers and students' perception of multicultural teaching associated with the perceived ethnic discrimination by peers and by teachers?

Q2 How is the ethnic composition of the student body associated with the perceived ethnic discrimination by peers and by teachers?

Q3 Does the relationship between multicultural policy, multicultural teaching and students' perception of multicultural teaching and the perceived ethnic discrimination by peers and by teachers differ according to ethnic composition? 


\section{Methods}

\subsection{Procedure and participants}

The data used is part of the Racism and Discrimination in Secondary Schools Survey (RaDiSS II). A multistage sampling frame was used in order to ensure sufficient variability and cases in terms of the level of urbanization of the school environment and students' ethnicity (for more information: Vervaet, 2018). The original study included 49 secondary schools that covered the entire range of ethnic composition from 0 to $95 \%$. Within these schools, the study focused on Grade 6 (comparable with Grade 12 in the American system). Students and teachers were asked to fill out a written questionnaire and principals filled out an online survey. In total, 3367 out of 4107 students completed the questionnaire, which equates to a response rate of $82 \%$. The only reason students did not participate was absence due to illness or a class being on a field trip. Students filled out the questionnaire in the presence of a researcher and one or more teachers. In order for the data to be linked to other information, the student questionnaires were not anonymous. However, all the students were informed that their names would be replaced by a code immediately and once the database was complete, all personal information would be deleted permanently. Teachers could fill out the questionnaire when and where they wanted and return it free of charge by post. In total, 669 out of 1584 teachers completed the questionnaire, amounting to a response rate of $42 \%$. Of the principals, 47 of the 49 completed the survey.

In this study, we use a sub-sample. In view of our research questions, we incorporated: (1) schools where the principal filled out the questionnaire; (2) schools where at least five teachers completed the questionnaire. This selection criterion was imposed to obtain a critical mass of respondents within each school, making generalizations about teachers more stable when creating a school culture measure (Goddard et al., 2001; Van Maele \& Van Houtte, 2011). This resulted in a sample size of 2715 students in 38 schools.

\subsection{Measures}

\subsubsection{Ethnic discrimination by peers and by teachers}

In the questionnaire, the students were presented with 11 potential experiences, five concerning their peers (e.g., another student excluded you), and six concerning their teachers (e.g., you are called on less in class than others are). This question was inspired by the work of Pachter et al. (2010). The students were asked if they had experienced each one of these situations since the beginning of Grade 4 (comparable with Grade 10 in the American system). If the response to one or more items was affirmative, the students were directed to indicate in the next question why they thought this happened. They could choose from 10 different options (e.g., appearance, doing your best at school, skin color). If their perceived reason did not match 
Table 1 Descriptive statistics for dependent and independent variables: frequencies (\%), means, standard deviations (SD) (Native Belgian students: Observations $\mathrm{N}=1866$, Students of other-than-Belgian descent: Observations $\mathrm{N}=849$, groups $\mathrm{N}=38$ )

\begin{tabular}{|c|c|c|c|c|}
\hline \multirow{2}{*}{$\begin{array}{l}\text { Variabele } \\
\text { Individual variables }\end{array}$} & \multicolumn{2}{|l|}{ Mean or $\%$} & \multicolumn{2}{|l|}{$\mathrm{SD}$} \\
\hline & Native Belgian & $\begin{array}{l}\text { Other-than- } \\
\text { Belgian } \\
\text { descent }\end{array}$ & Native Belgian & $\begin{array}{l}\text { Other-than- } \\
\text { Belgian } \\
\text { descent }\end{array}$ \\
\hline Ethnic discrimination by teachers & $0.9 \%$ & $20.3 \%$ & & \\
\hline Ethnic discrimination by peers & $3.6 \%$ & $16.0 \%$ & & \\
\hline $\begin{array}{l}\text { Ethnic discrimination by peers and/or } \\
\text { teachers }\end{array}$ & $4.1 \%$ & $29.6 \%$ & & \\
\hline Gender (male) & $50.6 \%$ & $50.6 \%$ & & \\
\hline Vocational track & $23.8 \%$ & $50.3 \%$ & & \\
\hline Technical track & $29.2 \%$ & $32.3 \%$ & & \\
\hline Academic track & $47.0 \%$ & $17.4 \%$ & & \\
\hline Socio-economic status & 55.11 & 41.96 & 15.92 & 15.90 \\
\hline Ethnicity & $68.7 \%$ & $31.3 \%$ & & \\
\hline $\begin{array}{l}\text { Students' perceptions of multicultural } \\
\text { teaching }\end{array}$ & 23.63 & 25.16 & 6.29 & 7.43 \\
\hline School variables & Mean or $\%$ & & $\mathrm{SD}$ & \\
\hline Low ethnic school concentration & 21.0 & & l & \\
\hline Medium ethnic school concentration & 47.4 & & l & \\
\hline High ethnic school concentration & 31.6 & & l & \\
\hline Multicultural policy & 2.68 & & 1.34 & \\
\hline Multicultural teaching & 3.01 & & 0.41 & \\
\hline
\end{tabular}

any of those presented, they could write something in a box labeled 'other reason'. Two reasons were categorized as ethnic discrimination, namely 'nationality/ethnicity' and 'skin color'. This question was asked one time in relation to their peers and one time in relation to their teachers. For the analyses, we created a categorical variable $(0=$ did not experience ethnic discrimination and $1=$ experienced ethnic discrimination). Table 1 presents detailed figures. As only $0.9 \%$ (=17 students) of the students of Belgian descent experienced discrimination by teachers, we decided to only focus on ethnic discrimination by peers for native Belgian students.

\subsection{Multicultural policy}

Multicultural policy is a self-reported measure by the principals about the school policy and consisted of an index of 6 items, specifically focused on embracing ethnic diversity (adapted from Vervaet et al., 2018a). Two example questions are "Does the school pay attention to Islamic holidays?" and "May foreign language students speak a language other than Dutch in the classroom?" The items are relevant to the Flemish context. The possible responses were yes $(=1)$, to a certain extent $(=2)$ and 
no $(=3)$. The variable is recoded into a dichotomous variable $(0=$ no; $1=$ yes/to a certain degree). The sum score on these 6 questions defined the degree of multiculturalism in school policy, with a higher score indicating a more multicultural policy. The mean score on multicultural policy was $2.68(S D=1.34)$.

\subsection{Multicultural teaching}

Multicultural teaching was measured by a 6-point Likert scale of 10 items (adapted from: Vervaet et al., 2018a, 2018b). Teachers self-reported the extent to which they use examples, data, and information from a variety of cultures and groups to illustrate key concepts, principles, generalizations, and theories in their subject area or discipline (Banks, 1993). The answer categories range from absolutely disagree $(=1)$ to completely agree $(=5)$ and not applicable $(=6)$. The last category was recoded to 1, because when teachers answered "not applicable", it is fair to assume that they did not pay attention to that item during their lessons. Two example items are: "During my lessons at school, I work explicitly on themes about differences between cultures" and "During my lessons at school, the many different cultures in our society are discussed". The scale was created by the mean scores on the 10 items, resulting in possible scores from 1 to 5 , with a higher score indicating that teachers practice more multicultural teaching. Exploratory factor analysis reveals that there is one underlying dimension. The item loadings range between 0.463 and 0.837 , and Cronbach's alpha for the multicultural teaching scale is 0.87 . Because we wanted to examine the role of a multicultural teacher culture, teachers' individual practices were aggregated to the school level. This can be achieved by calculating the mean value for each school (Hofstede et al., 1990; Van Houtte, 2004). We used the index of "mean rater reliability" (Glick, 1985; Shrout \& Fleiss, 1979), to ascertain whether the practice of multicultural teaching is indeed shared by the teachers in the same school. This index is based on the intra-class correlation (ICC) in a oneway analysis of variance, which measures the degree of resemblance between micro units belonging to the same macro unit (Snijders \& Bosker, 2011). The ICC is calculated by the formula: (Between Mean Square-Within Mean Square)/Between Mean Square (Shrout \& Fleiss, 1979). If this value is greater than 0.60, we can state that the practice of multicultural teaching is shared by teachers from the same school, and that it is therefore legitimate to speak of a multicultural culture at the school level (see also Van Houtte, 2004). For the measurement of multicultural teaching, this ICC is $0.72(F=3.572, p<0.001)$, showing that multicultural teaching is indeed shared by the teachers from the same school. The resulting measure of multicultural teacher culture has a mean of 3.01 with a minimum of 1 and a maximum of 5 $(S D=0.41$. (See Table 1).

\subsection{Students' perceptions of multicultural teaching}

Each student's perception of multicultural teaching was measured by a 5-point Likert scale of 10 items in parallel with the teacher scale (see above), but now from the perspective of the student (adapted from Vervaet et al., 2018b). Two sample 
items are: "How many of your teachers at school work explicitly on themes about differences between cultures?", and "How many of your teachers at school discuss the many different cultures in our society?" The possible answers were none of the teachers $(=1)$, one teacher $(=2)$, some teachers $(=3)$, most of the teachers $(=4)$, and all of the teachers $(=5)$. The scale was created by the sum scores on the 10 items, resulting in possible scores from 10 to 50, with a higher score indicating that pupils evaluate more of their teachers as practicing multicultural teaching. Exploratory factor analysis reveals that there is one underlying dimension. The item loadings range between 0.608 and 0.795 . Cronbach's alpha for this scale is 0.87 , with a mean score of $25.16(S D=7.43)$ for ethnic minority students and $23.63(S D=6.29)$ for ethnic majority students.

\subsection{Gender}

Gender is a dichotomous variable $($ male $=0$, female $=1$ ). Of the students in the sample, $49.4 \%$ identified as girls.

\subsection{Track}

The Flemish school system distinguishes between academic, technical, vocational and arts education. There were no students who followed arts education in this sample. Nearly one-third of the students in the sample $(32.1 \%)$ followed a vocational track, $30.2 \%$ a technical track and $37.8 \%$ an academic track. There are large differences between students of Belgian descent versus other-than-Belgian descent: for Belgian students, the percentages are $23.8 \%, 29.2 \%$ and $47 \%$ respectively, while for students with an immigrant background, this is $50.3 \%, 32.3 \%$ and $17.4 \%$. The overrepresentation of students with an immigrant background in the vocational track is in line with the large achievement gap in Flanders found in PISA (OECD, 2019).

\subsection{Socioeconomic status}

The socioeconomic status of students was measured using the International SocioEconomic Index of Occupational Status (ISEI) (Ganzeboom et al., 1992), derived from the International Standard Classification of Occupations (ISCO-88). This metric variable has a range from 16 to 90 . The highest score out of the two parents was used to measure the student's socioeconomic background. The mean score was 41.96 $(S D=15.90)$ for students of other-than-Belgian descent and $55.11(S D=15.92)$ for students of Belgian descent.

\subsection{Ethnicity}

The ethnicity of the students was assessed primarily by the birthplace of the student's maternal grandmother. This is common practice in Belgium, as most students of immigrant descent are second or third generation and have Belgian nationality (OECD, 2008). If this data was not available, we used their mother's nationality. In 
the event that all this data was missing, we used the birth country of the student. The sample consists of $68.7 \%$ of students of Belgian descent, $14.9 \%$ students of Turkish, Moroccan, North African, Middle Eastern or Central Asian descent, $4.1 \%$ of (South-) East European descent and 12.3\% of other parts of the world. This classification is inspired by the European Social Survey Classifications and Coding Standards (ESS7-2014) and meaningful immigrant groups in Belgian society.

\subsection{Ethnic school composition}

Ethnic composition at the school level is a variable based on the ethnicity of every student (as explained above). First, the proportion of students of other-than-Belgian descent in Grade 6 was calculated. Second, we created a categorical variable with three categories: low proportion of students with other-than-Belgian ethnicity (less than 15\%), medium proportion (between 15 and 49.9\%) and high proportion (between 50 and $100 \%$ ). The range of the proportion of students with an ethnic origin outside of Belgium goes from 0 until 0.95 . In the sample, $21 \%$ of the schools have a low concentration, $47.4 \%$ a medium concentration and $31.6 \%$ a high concentration.

\subsection{Analytic strategy}

Given that students are nested in schools and the dependent variable is dichotomous, we conducted logistic multilevel analyses (MIWin 3.04, 2nd order PQL estimation). We opted to carry out separate analyses for students of Belgian descent and students of other-than-Belgian descent groups, as this allows us to get a clear insight into the full model for each group. Each analysis was started with an estimation of the unconditional model in order to estimate the amount of variance in ethnic discrimination within schools and between schools. However, with a dichotomous outcome variable there are different methods to calculate which proportion of the total residual variance is attributable to level 2 and these methods give different results (Austin $\&$ Merlo, 2017; Rasbash et al. 2020). We chose a widely used method based on the latent response formulation of the model, however, this should be interpreted not as an exact number, but rather as an indication of the importance of school contextual variables in explaining perceived ethnic discrimination. Furthermore, the betweenschool variance component and its standard error estimated in the unconditional model give an idea of whether or not the between-school variance is significant. In the next step, the control variables were added. These control variables have been demonstrated to relate to ethnic discrimination, namely gender, socio-economic status, ethnicity (analysis of other than Belgian descent students) and track (Bellmore et al., 2012; Brown \& Chu, 2012; Van Praag et al., 2015; Verkuyten \& Thijs, 2002b). To answer research question 1 , the three indicators of multicultural education were added next: multicultural policy and multicultural teaching as school-level features; and the perception of multicultural teaching as a student-level feature. To answer research question 2 , we added ethnic composition as a school-level feature in model 3. In the next steps, to answer research question 3, we tested if ethnic composition 
and the three different components of multicultural education interacted. Throughout the different analyses, prudence in interpreting and comparing log-odd ratios was necessary, considering that carrying out a logistic regression causes limitations due to the fixed unobserved heterogeneity (Mood, 2010). All metric variables were grand mean centred. A random intercept model was used.

\section{Results}

\subsection{Descriptive analysis}

The descriptive results (Table 1) showed large differences between the reported ethnic discrimination by native Belgian students and students with an immigrant background. While very few native Belgian students reported discrimination by teachers $(0.9 \%)$ or by peers $(3.6 \%)$, almost one out of five students with an immigrant background reported being discriminated against by teachers $(20.3 \%)$ and one out of six by peers (16\%). When we took a closer look at the group of students with an immigrant background who had experienced both teacher and peer discrimination, we saw that $6.7 \%$ of these students experienced both, and hence, $13.5 \%$ only teacher discrimination and $9.3 \%$ only peer discrimination.

\subsection{Native Belgian students}

The unconditional multilevel analysis indicated that $16.2 \%\left(\mathrm{~s}^{2} \mathrm{u}=0.638, S E=0.306\right.$, $\mathrm{s}^{2} \mathrm{e}=3.29$ ) of the variance of ethnic discrimination is situated at the school level (Table 2). Model 1 shows that for girls compared to boys the odds of experiencing discrimination versus no discrimination was $0.315(p<0.001)$, hence, girls are less likely than boys to experience discrimination. Students in the technical track and vocational track are more likely to experience discrimination than students in the academic track. There is no significant effect of socio-economic status. Model 2 gives us the results to answer research question 1 (the role of multicultural education) and shows mixed findings. Ethnic majority students' perception of multicultural teaching is not related with perceived ethnic discrimination. The effect of multicultural teaching culture is borderline significant: in schools where teachers report paying more attention to multiculturalism, there is a higher likelihood of native Belgian students indicating that they feel discriminated against $(O R=1.923, p=0.08)$. This is in line with the effect of the multicultural policy: The multicultural policy has a positive and significant impact on perceived ethnic discrimination. For a oneunit increase in the direction of a more multicultural welcoming school policy, the odds are multiplied by 1.381 ( $p<0.001)$. Model 3 focuses on the research question 2 and the ethnic composition. In line with the imbalance of power thesis, we find that a student body that consists of more students with an immigrant background raises the probability that native Belgian students will report being discriminated against, however, this is only the case if more than half of the student population consists of students with an immigrant background (for high concentration: $O R=4.039$, 


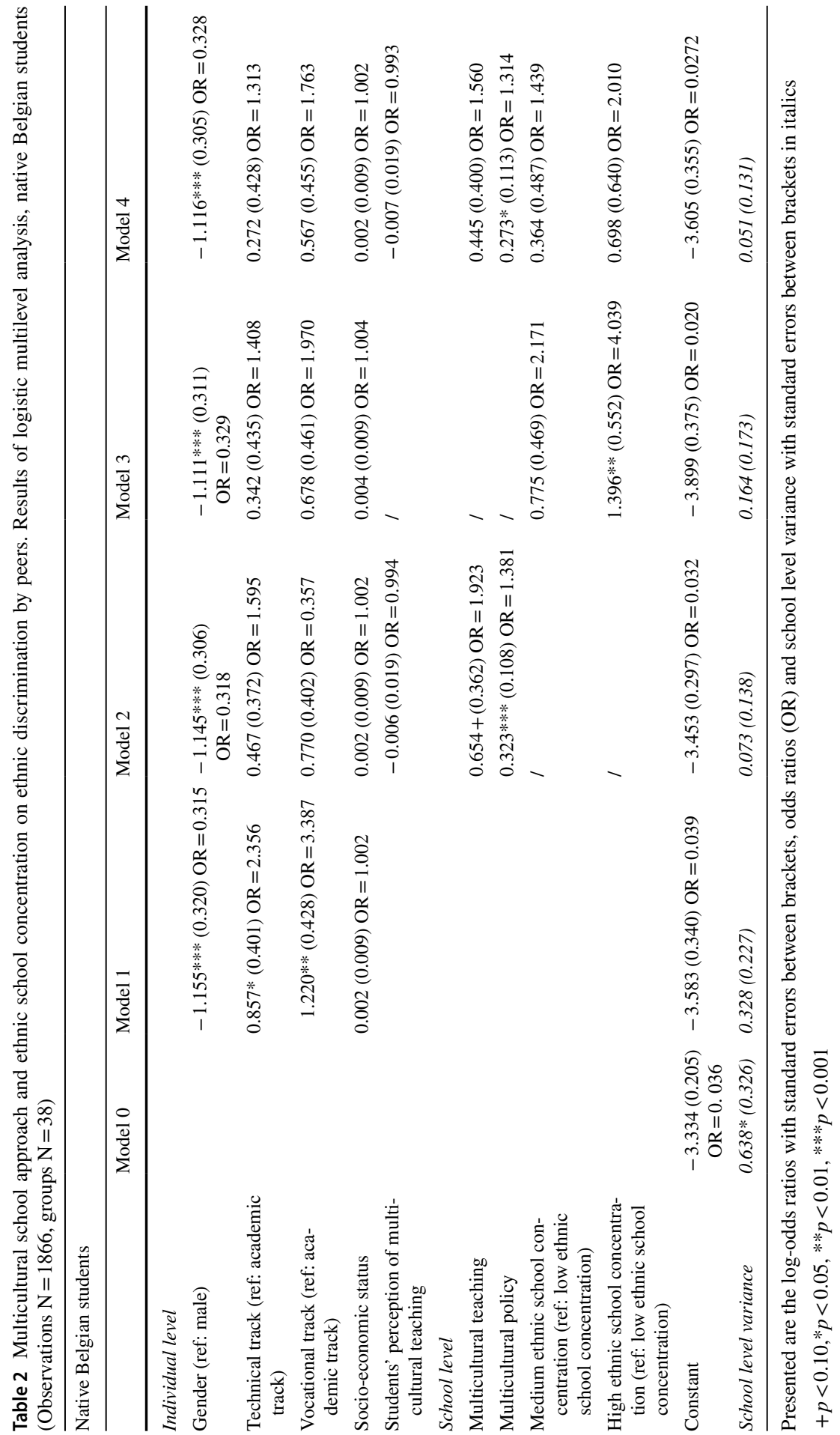


$p<0.01$ ). In the next step, we explored research question 3, whether the ethnic school composition moderated the relationship between the three indicators of multicultural education and ethnic discrimination, but this is for none of the indicators the case. However, when we add all four explanatory variables at the same time, the main effects shift. The multicultural policy is the only significant effect that remains. Multicultural teaching culture is no longer significant and the same happened to ethnic school concentration. As we performed logistic analyses, no hard conclusions can be drawn, but it could be related to the fact that teachers in schools with more students with an ethnic background tend to pay more attention to multiculturalism.

\subsection{Students of other-than-Belgian descent}

The results in Tables 3 and 4 apply to the students with an immigrant background and differentiate between ethnic discrimination by teachers and by peers. We first discuss ethnic discrimination by teachers (Table 3). The unconditional model shows that $7.7 \%\left(\mathrm{~s}^{2} \mathrm{u}=0.278, S E=0.137, \mathrm{~s}^{2} \mathrm{e}=3.29\right)$ of the variance in ethnic discrimination was situated at the school level. Model 1 shows that ethnic background matters and that students of Turkish, Moroccan, North African, Middle Eastern or Central Asian descent are the group of students that are more likely to report ethnic discrimination by teachers than students of (South) Eastern-European descent $(O R=0.221$, $p<0.001$ ) or students that have a migration history in other parts of the world $(O R=0.342, p<0.001)$. Girls are less likely to experience ethnic discrimination than boys $(O R=367, p<0.001)$. Track and socio-economic status are not significantly associated with ethnic discrimination. Model 2 focuses on the three indicators of multicultural education and there are mixed findings. No significant association can be found between multicultural teaching culture and perceived ethnic discrimination, but there is a significant effect of students' perception of multicultural teaching and multicultural school policy. When students perceive their teachers as paying more attention to multiculturalism in their lessons, they are less likely to report ethnic discrimination $(O R=0.951, p<0.001)$. The opposite is true for multicultural policy. Schools with more multicultural-oriented policy seem to enhance the reports of ethnic discrimination $(O R=1.218, p<0.005)$. Research question 2 (the role of ethnic composition) has to be answered negatively: No relationship between ethnic composition and ethnic discrimination was found. In the final step, we explored the interaction terms between the three multiculturalism measures and ethnic composition to answer research question 3, but no significant interaction effects were found, nor were there shifts in the main effects.

Second, we focused on ethnic discrimination by peers. The unconditional model showed that only $0.5 \%$ of the variance of ethnic discrimination by peers is situated at the school level and this is not significant $\left(s^{2} u=0.017, S E=0.069, s^{2} e=3.29\right)$. Due to the insignificance of this low percentage, we applied multilevel modeling to account for the clustered data, but we did not take into account school-level variables. The low variance at the school level, immediately answered the first and part of the second research question. The ethnic school composition, multicultural policy and multicultural teaching have no impact on perceived ethnic discrimination 


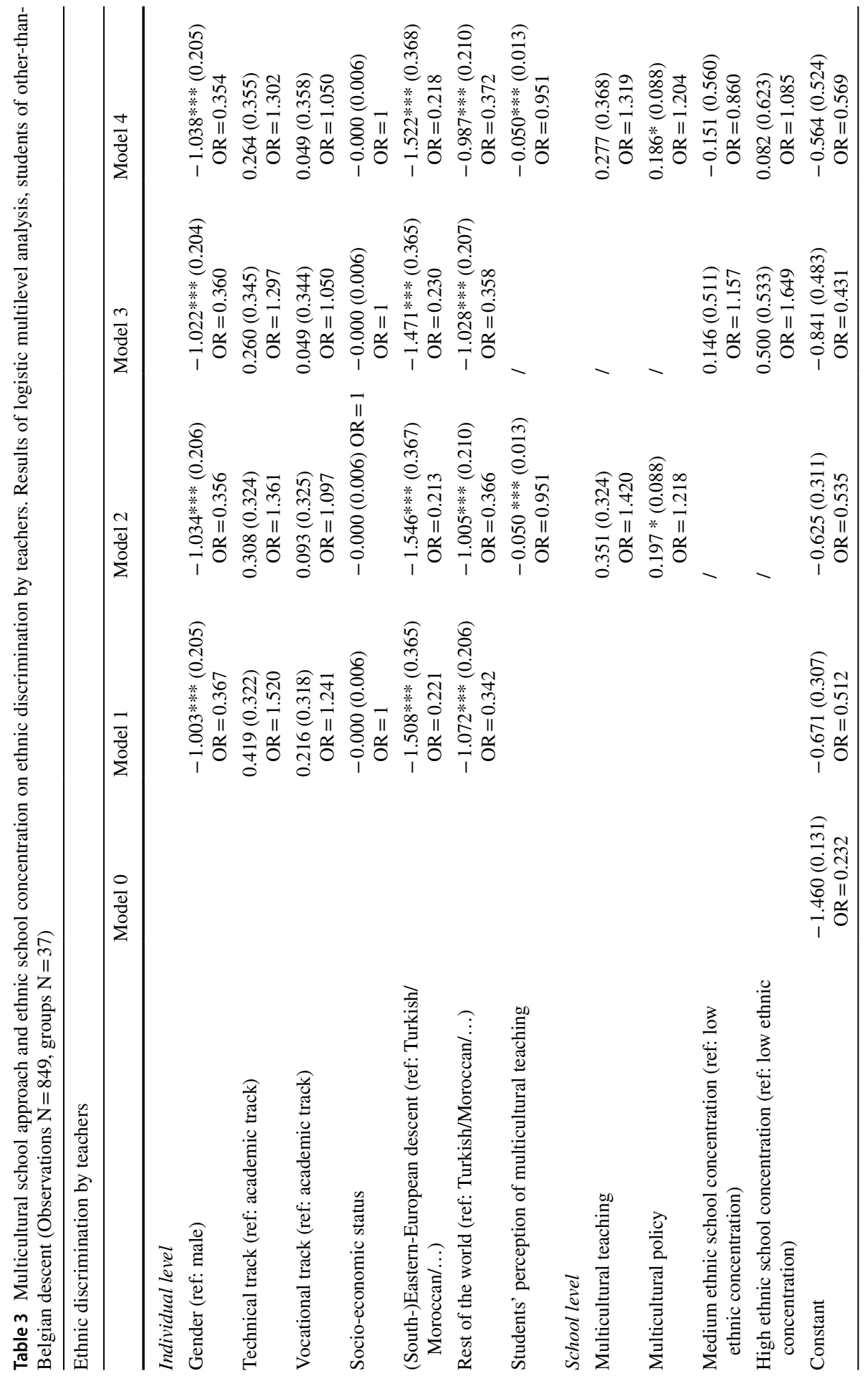




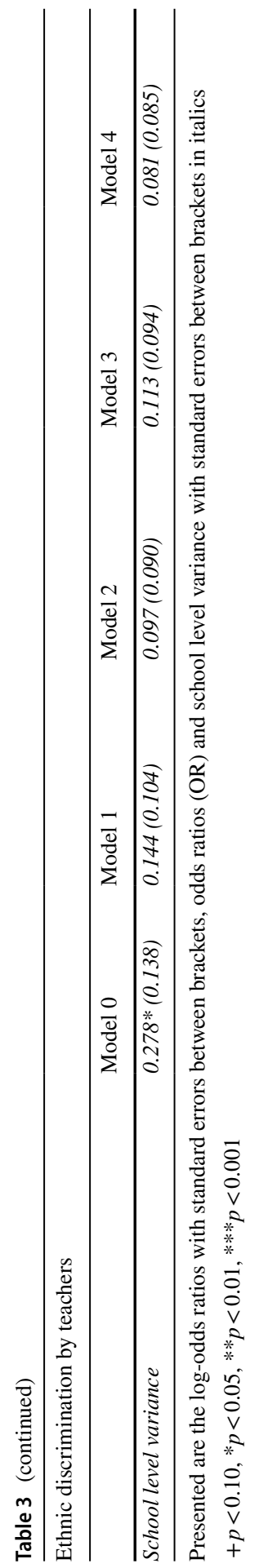




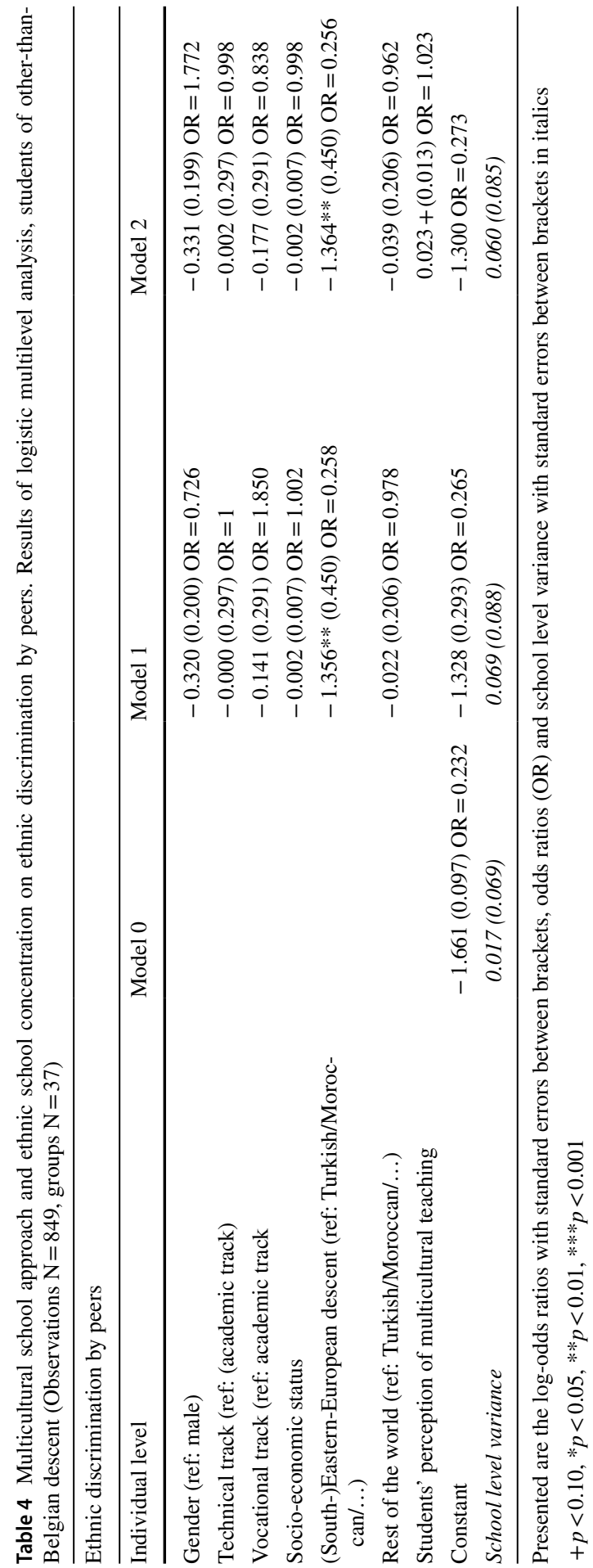


by peers. Students' perception of multicultural teaching is borderline significant, with students who perceive their teachers as teaching in a more multicultural way being more likely to indicate that they feel discriminated against $(O R=1.023$, $p<0.10$ ). Additionally, Models 1 and 2 show that students of Turkish, Moroccan, North African, Middle Eastern or Central Asian descent are more likely to report ethnic discrimination by peers than students of (South) Eastern-European descent $(O R=0.256, p<0.01)$, but not in comparison with students that have an immigrant history involving other parts of the world.

\section{Discussion}

The purpose of this study was to gain better insight into how a multicultural school context shapes the experience of ethnic discrimination by peers and teachers for ethnic majority and minority students. This is important, since ethnic discrimination is a very harmful experience for adolescents, but little is known about the influence of the school. We focused on three indicators of multicultural education-multicultural policy as perceived by the principal, multicultural teaching as perceived by the teachers and students' perception of multicultural teaching and the ethnic student composition of the school. Next to gaining insight into how these features are related with perceived ethnic discrimination, we explored if the ethnic composition interacted with the three components of multicultural education.

Almost one out of three $(29.6 \%)$ of the students with an immigrant background self-reported that they experienced ethnic discrimination by teachers and/or fellow students. Although this number is a reflection of the perceived discrimination and not the exact number of discriminatory incidents, this number shows that discrimination is not a phenomenon in the margins, but central in many adolescents' lives. The high number is reason for concern, especially the fact that $20.3 \%$ of the students indicate that they experience ethnic discrimination by teachers. Previous research has shown the negative impact of teacher discrimination on minority student school outcomes (D'hondt et al., 2015), but teachers who openly show discriminatory behaviour in the classroom also decrease the overall learning abilities of the students as teachers' negative emotions limit the emotional and academic competences of all students (Valiente et al., 2020). Moreover, teaching is a moral endeavour and as a consequence teachers might indirectly socialize students into believing that discriminatory behaviour is acceptable (Lumpkin, 2008; Fallona, 2000). Ethnic discrimination among native Belgian students is possible as well, but it is much rarer, particularly discrimination coming from teachers. In theory everybody can become the victim of ethnic discrimination as we all have an ethnicity, but these figures show that the power of belonging to the dominant ethnic group in society cannot be underestimated.

For students with an immigrant background there is no school variance found in the reports of ethnic discrimination by peers, which already answers for a large part the research questions. On the one hand, this could be interpreted as ethnic discrimination being a highly individual experience influenced by individual factors. This does not necessarily mean that teachers' efforts to pay attention to multiculturalism 
or multicultural policy cannot make a difference. It is very plausible that there are mechanisms at play between the multicultural efforts at school level and the perceived ethnic discrimination by peers at student level that yield different outcomes for different individuals. Hence, we cannot state that multicultural teaching or multicultural policy has no influence, but rather that students internalize these efforts in different ways. This results in the phenomenon that no variance between schools can be found, because there is not a clear pattern in perceived ethnic discrimination that varies from school population to school population according to the applied multicultural education. On the other hand, ethnic discrimination is not an isolated experience within school for these youngsters. Discrimination is a wide-spread societal phenomenon and secondary schools are not the only setting in the lives of adolescents. This is especially true for ethnic discrimination that occurs among adolescents themselves, as they interact with each other outside of school as wellon public transport, in the neighbourhood, on social media or in sports clubs. This wider societal reality of constant potential interethnic tensions among peers might diminish the effect that schools can have on the experience of ethnic discrimination by peers towards ethnic minority students. This could also explain why there is school variance with respect to ethnic discrimination by teachers, as this relationship is specifically related to the school context.

There is no such thing as 'the' effect of multicultural education. As shown in other studies, a multicultural approach consists of different elements represented and perceived by different actors within a school and all of these elements have their own (sometimes contradicting) effect. For ethnic minority students, it is the students' perception of multicultural teaching that matters, not the teaching culture itself. One element that could explain this finding (partly) is that in secondary education the general teaching culture is less effective in explaining ethnic discrimination, because students have different teams of teachers. Teachers will most likely differ in their effectiveness and motivation to teach from a multicultural perspective, hence, the individual perception of the students captures potentially better both the quality and the quantity to which the student is exposed to multicultural teaching.

Furthermore, since this study relies on self-reported measures of multicultural teaching, it is not only the incident that is being measured, but also the interpretation. How is this multicultural message being received by this student? These results clearly indicate that the perception is important to take into account. If individual students with an immigrant background feel that their teachers pay more attention to multiculturalism in their teaching, they are less likely to report being discriminated against by their teachers, but more so by their peers. Hence, how students perceive their teachers' multicultural efforts is negatively correlated with perceived discrimination by teachers, but positively correlated with perceived discrimination by peers. This finding could be seen as a confirmation of the idea that multicultural teaching has a direct positive impact on the inter-ethnic relationship between non-native Belgian students and their teachers. In addition, since we measure the perceived discrimination, it confirms the idea that multicultural education is most likely also helping students to raise their awareness to the existence of ethnic discrimination and to support them in correctly labeling negative interactions with their fellow students as being discriminatory. The same is true for the relationship between multicultural 
policy and perceived ethnic discrimination. The results show a positive relationship. In schools where principals have a more welcoming multicultural policy, students are more likely to indicate that they feel discriminated against.

These findings give rise to a post-hoc reflection about the role that threat might play. A welcoming diversity-policy in the sense that for example a non-native language is allowed to be spoken or it is possible to wear a headscarf (religious symbol of Islam, while Catholicism is the dominant religion) can give rise to feelings of threat among ethnic majority students (Plaut et al., 2018). An experimental study among White adults in the USA showed that multiculturalism evokes a feeling of exclusion among Whites (Plaut et al., 2011), whereby the question "What about me?" surfaces. This is especially the case when the ethnic majority does not obtain the intended message from a multicultural approach (Rios \& Wynn, 2016). A school policy is often mainly something that students just have to accept passively, and hence, could be an ideal source of feelings of exclusion. More generally, multiculturalism may be perceived as a challenge for the dominant position of the nativeBelgian students. It questions the boundary of group exclusiveness and challenges their power and privilege (Blumer, 1958). When the dominant group has the feeling that their privileged position is under threat, this is the ideal condition for ethnic prejudice and by consequence, ethnic discrimination. This resulting feeling of threat is also in line with the results of multicultural teaching culture and multicultural policy for ethnic majority students. A more multicultural teaching culture is related with more feelings of being discriminated against by peers. A more multicultural school policy is also positively related with feeling discriminated against.

These analyses cannot verify if this is related with the explanation of raised awareness or with feelings of threat. An in-depth qualitative research design is necessary to disentangle the underlying dynamics of the finding that certain aspects of multicultural education are related with more reports of being discriminated against for ethnic majority and minority students. Is it a consequence of feelings of threat of the ethnic majority students that leads to more inter-ethnic conflict? And/or does this kind of policy just make ethnicity more salient and are the reports a consequence of raised awareness rather than an effective rise in the number of instances of discrimination? Or do principals and teachers try to resolve interethnic conflict by paying more attention to multiculturalism?

Although perceived ethnic discrimination by peers is rare for ethnic majority students, it is clear that native-Belgian students are more likely to indicate ethnic discrimination when the number of students with an immigrant background rises. In line with the imbalance of power thesis, the numerical composition of the student body can create different power dynamics that shift the chances of feeling discriminated against. The make-up of the student body did not influence the reported ethnic discrimination by teachers for ethnic minority students, as teachers do not become 'more powerful' because of it. Flemish teachers belong for the large part to the ethnic majority and have a position of authority in the classroom.

The interaction between multicultural education and ethnic composition appeared not to be significant. The effect of multicultural education does not differ according to the number of students with an immigrant background. However, as schools are complex settings where different actors, cultures, policies and climates all play roles, 
we are convinced that future research should stay focused on how multicultural education interacts with structural and compositional school characteristics. Nobody wants the effects of multicultural education to be undone or diminished by another school policy or characteristic. Hence, future studies should look at interactions to push the understanding on how school environments as a whole can become more conducive to improving intergroup / interethnic relations.

\subsection{Limitations and future research}

The cross-sectional character of this study limits the possibilities to obtain a good understanding of how a multicultural school context affects the experience of ethnic discrimination. An ideal research situation would be to have a longitudinal research design where the school changes in ethnic composition of the student population or starts/intensifies multicultural education to get detailed insights in how these school factors influence the experience of ethnic discrimination. Another element to take into account is the fact that self-report measures were used. This is a very common method with many benefits, but it is important that the reader is aware is of this when interpreting the results. First, the students report on their experience of ethnic discrimination. Because this measure captures the lived experience of the student, one cannot draw firm conclusions about the actual number of incidents. Second, multicultural education is a self-report measure from the perspective of three actors: principal, teacher and student. Since these measures focus on a normative issue, the measure for principals and teachers can be potentially biased due to social desirability (Verkuyten \& Thijs, 2002b). That is why we opted to include the perception of the student, since this captures the students' lived experience of multicultural teaching. Furthermore, for multicultural teaching, there is the complexity of developing a reliable contextual measure, because in secondary education each individual student can have a different set of teachers depending on the subjects s/he follows. The inclusion of the perception of the student and the fact that we chose to work with a culture measure based on the average of the responses of the teachers, can help to compensate for this shortcoming. Although this culture measure is a valid proxy for the multicultural teacher culture present in that school, a measure where you could link the score of the specific teacher team to the particular students would be better.

For future research, it would be interesting to make use of a mixed-methods approach. In this study, we already combine the reports of different actors within a school, but the use of both qualitative and quantitative techniques could deepen the insights and reinforce conclusions. Qualitative observations can give a researcherperspective on discriminatory incidents in a school and the multicultural approach a school employs. Qualitative interviews can help to disentangle the elements that influence the interpretation of multicultural education by the students and the perception of a situation as discriminatory (e.g., Mansouri \& Trembath, 2005; Stevens, 2009). These insights could then be complemented by a large-scale quantitative study to get a full picture of how a multicultural school approach impacts the perception of ethnic discrimination. Another suggestion for future research is to focus on how ethnic majority students react to multicultural education by combining different 
outcomes, such as ethnic discrimination, threat, prejudice, feelings of exclusion, etc. We find it important to take the whole student body into account, but a specific focus on ethnic majority students would help to understand the different dynamics that are at play when ethnic majority students are confronted with multicultural education.

\section{Conclusion}

In conclusion, this study builds on the knowledge of how school characteristics are related with students' perceived ethnic discrimination. First, the results confirm the importance of power dynamics in relation to ethnic discrimination, both the power of belonging to the dominant ethnic group in society and the numerical power within the walls of a school. However, the latter only applies to ethnic majority students.

Second, by taking into account three different perspectives on multicultural education in one study, we found clear evidence of the complex and multi-faceted character of multicultural education. Although one of the main goals of multicultural education is to combat racism and discrimination, our study shows that this is not easy to achieve. For example, multicultural education can be related with more perceived ethnic discrimination. Although this effect could indicate a rise in awareness rather than of a rise in the discriminatory incidents per se, this does not make the experience less real for the students. Future research should focus on the necessary conditions to make multicultural education successful in combating racism and discrimination.

The lessons that can be taken from this research is that an all-encompassing approach is necessary. A policy document written by the principal can have a completely different effect on students compared to their teachers' efforts to incorporate multiculturalism in their lessons, although both actions are focused on valuing diversity. That is to say that it is not only about the underlying philosophy, but also about how it is executed and perceived. Furthermore, in order to ensure that the efforts of one person are not undone by another person, the whole school has to collaborate to make multicultural education a success.

Another lesson is that the dynamics are different for discrimination by peers and by teachers, as well as different for ethnic majority and minority students. Our research suggests that for ethnic minority students, the school context is especially important in understanding and influencing the relationship between students and teachers. For a good understanding of the experience of discrimination by peers, researchers should focus more on individual-level antecedents. For ethnic majority students, the attention to multicultural education seems to raise feelings of ethnic discrimination. As a result, schools have to be aware of not overlooking negative consequences of their multicultural efforts for the ethnic majority students, since they could potentially aggravate interethnic tensions instead of improving them.

Author contributions All authors contributed to the study conception and design. Material preparation, data collection and analysis were performed by Fanny D'hondt and Roselien Vervaet. The first draft of 
the manuscript was written by Fanny D'hondt and all authors commented on previous versions of the manuscript. All authors read and approved the final manuscript.

Funding Funded by Research Foundation-Flanders as part of the research projects: Strategic Basic Research-S004119N, G062114N and G024516N.

Data availability Available upon request from the authors.

Code availability Available upon request from the authors.

\section{Declarations}

Conflict of interest Not applicable.

Open Access This article is licensed under a Creative Commons Attribution 4.0 International License, which permits use, sharing, adaptation, distribution and reproduction in any medium or format, as long as you give appropriate credit to the original author(s) and the source, provide a link to the Creative Commons licence, and indicate if changes were made. The images or other third party material in this article are included in the article's Creative Commons licence, unless indicated otherwise in a credit line to the material. If material is not included in the article's Creative Commons licence and your intended use is not permitted by statutory regulation or exceeds the permitted use, you will need to obtain permission directly from the copyright holder. To view a copy of this licence, visit http://creativecommons.org/licen ses/by/4.0/.

\section{References}

Agirdag, O., Demanet, J., Van Houtte, M., \& Van Avermaet, P. (2011). Ethnic school composition and peer victimization: A focus on the interethnic school climate. International Journal of Intercultural Relations, 35(4), 465-473. https://doi.org/10.1016/j.ijintrel.2010.09.009

Agirdag, O., Merry, M. S., \& Van Houtte, M. (2016). Teachers' understanding of multicultural education and the correlates of multicultural content integration in flanders. Education and Urban Society, 48(6), 556-582. https://doi.org/10.1177/0013124514536610

Al Sadi, F. H., \& Basit, T. N. (2012). Religious tolerance in Oman: Addressing religious prejudice through educational intervention. British Educational Research Journal, 1-26. https://doi.org/10. 1080/01411926.2011.652071.

Apfelbaum, E. P., Pauker, K., Sommers, S. R., \& Ambady, N. (2010). In blind pursuit of racial equality? Psychological Science, 21(11), 1587-1592. https://doi.org/10.1177/0956797610384741

Aragón, O. R., Dovidio, J. F., \& Graham, M. J. (2017). Colorblind and multicultural ideologies are associated with faculty adoption of inclusive teaching practices. Journal of Diversity in Higher Education, 10(3), 201. https://doi.org/10.1037/dhe0000026

Austin, P. C., \& Merlo, J. (2017). Intermediate and advanced topics in multilevel logistic regression analysis. Statistics in Medicine, 36(20), 3257-3277. https://doi.org/10.1002/sim.7336

Banks, J. (1993). Multicultural education : historical development, dimensions, and practice. Review of Research in Education, 19(1993), 3-49.

Bellmore, A., Nishina, A., You, J.-I., \& Ma, T.-L. (2012). School context protective factors against peer ethnic discrimination across the high school years. American Journal of Community Psychology, 1-2, 98-111. https://doi.org/10.1007/s10464-011-9443-0

Benner, A. D., \& Graham, S. (2011). Latino Adolescents' experiences of discrimination across the first 2 years of high school: Correlates and influences on educational outcomes. Child Development, 82(2), 508-519. https://doi.org/10.1111/j.1467-8624.2010.01524.x

Benner, A. D., \& Graham, S. (2013). The antecedents and consequences of racial/ethnic discrimination during adolescence: Does the source of discrimination matter? Developmental Psychology, 49(8), 1602-1613. https://doi.org/10.1037/a0030557 
Benner, A. D., Wang, Y., Shen, Y., Boyle, A. E., Polk, R., \& Cheng, Y. P. (2018). Racial/ethnic discrimination and well-being during adolescence: A meta-analytic review. American Psychologist, 73(7), 855-883. https://doi.org/10.1037/amp0000204

Bennett, C. I. (2001). Genres of research in multicultural education. Review of Educational Research, 71(2), 171-217. https://doi.org/10.3102/00346543071002171

Bennett, C. I., Niggle, T., \& Stage, F. (1990). Preservice multicultural teacher education: Predictors of student readiness. Teaching and Teacher Education, 6(3), 243-254. https://doi.org/10.1016/0742051X(90)90016-X

Blumer, H. (1958). Race prejudice as a sense of group position. The Pacific Sociological Review, 1(1), 3-7.

Brown, C. S., \& Chu, H. (2012). Discrimination, ethnic identity, and academic outcomes of mexican immigrant children: The importance of school context. Child Development, 83(5), 1477-1485. https://doi.org/10.1111/j.1467-8624.2012.01786.x

De Meyer, I., Janssens, R., Warlop, N., Van Keer, H., De Wever, B., \& Valcke, M. (2018). Leesvaardigheid van 15-jarigen - Vlaams Rapport PISA2018. (Reading ability of 15-year olds - Flemish Report PISA2018). Universiteit Gent. https:/www.pisa.ugent.be/uploads/assets/155/1575373055716-Leesv aardigheid_OverzichteersteresultatienPISA2018.pdf.

D'hondt, F., Van Houtte, M., \& Stevens, P. A. J. (2015). How does ethnic and non-ethnic victimization by peers and by teachers relate to the school belongingness of ethnic minority students in Flanders, Belgium? An explorative study. Social Psychology of Education, 18(4), 685-701. https://doi.org/10.1007/s11218-015-9304-z

Fallona, C. (2000). Manner in teaching: A study in observing and interpreting teachers' moral virtues. Teaching and Teacher Education, 16(7), 681-695. https://doi.org/10.1016/S0742-051X(00)00019-6.

Fisher, C. B., Wallace, S. A., \& Fenton, R. E. (2000). Discrimination distress during adolescence. Journal of Youth and Adolescence, 29(6), 679-695. https://doi.org/10.1023/A:1026455906512

Flemish Ministry of Education and Formation. (2020). Ontwerp van decreet betreffende de onderwijsdoelen voor de tweede en de derde graad van het secundair onderwijs. (Draft decree on educational objectives for the second and third stage of secondary education). https://www.vlaamsparl ement.be/parlementaire-documenten/parlementaire-initiatieven/1459646.

Ganzeboom, H. B. G., De Graaf, P. M., \& Treiman, D. J. (1992). A standard international socio-economic index of occupational status. Social Science Research, 21, 1-56. https://doi.org/10.1016/ 0049-089X(92)90017-B

Geerlings, J., Thijs, J., \& Verkuyten, M. (2019). Preaching and practicing multicultural education: Predicting students' outgroup attitudes from perceived teacher norms and perceived teacherclassmate relations. Journal of School Psychology, 75(July), 89-103. https://doi.org/10.1016/j. jsp.2019.07.003

Gillborn, D. (2003). Race, ethnicity and education: Teaching and learning in multi-ethnic schools. Routledge.

Glick, W. H. (1985). Conceptualizing and measuring organizational and psychological climate: Pitfalls in multilevel research. Academy of Management Review, 10(3), 601-616. https://doi.org/10. 5465/amr. 1985.4279045

Goddard, R. D., Tschannen-Moran, M., \& Hoy, W. K. (2001). A multilevel examination of the distribution and effects of teacher trust in students and parents in urban elementary schools. The Elementary School Journal, 102(1), 3-17. https://doi.org/10.1086/499690

Graham, S. (2006). Peer victimization in school: Exploring the ethnic context. Current Directions in Psychological Science, 15(6), 317-321. https://doi.org/10.1111/j.1467-8721.2006.00460.x

Graham, S. (2018). Race/ethnicity and social adjustment of adolescents: How (Not if) school diversity matters. Educational Psychologist, 53(2), 64-77. https://doi.org/10.1080/00461520.2018.14288 05

Gregory, A., \& Ripski, M. B. (2008). Adolescent trust in teachers: Implications for behavior in the high school classroom. School Psychology Review, 37(3), 337-353. https://doi.org/10.1080/02796015. 2008.12087881

Hebl, M., Cheng, S. K., \& Ng, L. C. (2020). Modern discrimination in organizations. Annual Review of Organizational Psychology and Organizational Behavior, 7(1), 257-282. https://doi.org/10.1146/ annurev-orgpsych-012119-044948

Hofstede, G., Neuijen, B., Ohayv, D. D., \& Sanders, G. (1990). Measuring organizational cultures: A qualitative and quantitative study across twenty cases. Administrative Science Quarterly, 286316. https://doi.org/10.2307/2393392. 
Juvonen, J., Kogachi, K., \& Graham, S. (2018). When and how do students benefit from ethnic diversity in middle school? Child Development, 89(4), 1268-1282. https://doi.org/10.1111/cdev.12834

Juvonen, J., Nishina, A., \& Graham, S. (2006). Ethnic diversity and perceptions of safety in urban middle schools. Psychological Science, 17(5), 393-400. https://doi.org/10.1111/j.1467-9280.2006.01718.x

Khalifa, M. A., Gooden, M. A., \& Davis, J. E. (2016). Culturally responsive school leadership: A synthesis of the literature. Review of Educational Research, 86(4), 1272-1311. https://doi.org/10.3102/ 0034654316630383

Lumpkin, A. (2008). Teachers as role models teaching character and moral virtues. Journal of Physical Education, Recreation \& Dance, 79(2), 45-50. https://doi.org/10.1080/07303084.2008.10598134.

Major, B., Quinton, W., \& McCoy, S. (2002). Antecedents and consequences of attributions to discrimination: Theoretical and empirical advances. Advances in Experimental Social Psychology, 34, 251-330.

Mansouri, F., \& Trembath, A. (2005). Multicultural education and racism: The case of Arab-Australian students in contemporary Australia. International Education Journal, 6(4), 516-529.

Meeussen, L., Otten, S., \& Phalet, K. (2014). Managing diversity: How leaders' multiculturalism and colorblindness affect work group functioning. Group Processes \& Intergroup Relations, 17(5), 629644. https://doi.org/10.1177/1368430214525809

Mood, C. (2010). Logistic regression: Why we cannot do what we think we can do, and what we can do about it. European Sociological Review, 26(1), 67-82. https://doi.org/10.1093/esr/jcp006.

OECD. (2008). Jobs for immigrants: Labour market integration in Belgium, France, the Netherlands and Portugal. OECD Publishing.

OECD. (2016). PISA 2015 results (Volume I): Excellence and equity in education. OECD Publishing.

OECD. (2019). PISA 2018 insights and interpretations. OECD Publishing.

Pachter, L. M., Bernstein, B. A., Szalacha, L. A., \& Coll, C. G. (2010). Perceived racism and discrimination in children and youths: An exploratory study. Health \& Social Work, 35(1), 61-69. https://doi. org/10.1093/hsw/35.1.61

Pager, D., \& Shepherd, H. (2008). The sociology of discrimination: racial discrimination in employment, housing, credit, and consumer markets. Annual Review of Sociology, 34(1), 181-209. https://doi. org/10.1146/annurev.soc.33.040406.131740

Patrick, H., Anderman, L. H., Ryan, A. M., Edelin, K. C., \& Midgley, C. (2001). Teachers' communication of goal orientations in four fifth-grade classrooms. Elementary School Journal, 102(1), 35-58. https://doi.org/10.1086/499692

Pettigrew, T. F. (1998). Intergroup contact theory. Annual Review of Psychology, 49, 65-85. https://doi. org/10.1146/annurev.psych.49.1.65

Plaut, V. C., Garnett, F. G., Buffardi, L. E., \& Sanchez-Burks, J. (2011). "What about me?” Perceptions of exclusion and Whites' reactions to multiculturalism. Journal of Personality and Social Psychology, 101(2), 337. https://doi.org/10.1037/a0022832

Plaut, V. C., Thomas, K. M., Hurd, K., \& Romano, C. A. (2018). Do color blindness and multiculturalism remedy or foster discrimination and racism? Current Directions in Psychological Science, 27(3), 200-206. https://doi.org/10.1177/0963721418766068

Quillian, L. (1995). Prejudice as a response to perceived group threat: Population composition and antiimmigrant and racial prejudice in Europe. American Sociological Review, 586-611. https://doi.org/ $10.2307 / 2096296$.

Rasbash, J., Steele, F., Browne, W. J., \& Goldstein, H. (2020). A user's guide to MLwiN-Version 3.05. http://www.bristol.ac.uk/cmm/media/software/mlwin/downloads/manuals/3-05/manual-print.pdf.

Rios, K., \& Wynn, A. N. (2016). Engaging with diversity: Framing multiculturalism as a learning opportunity reduces prejudice among high White American identifiers. European Journal of Social Psychology, 46(7), 854-865. https://doi.org/10.1002/ejsp.2196

Shrout, P. E., \& Fleiss, J. L. (1979). Intraclass correlations: Uses in assessing rater reliability. Psychological Bulletin, 86(2), 420-428.

Snijders, T. A., \& Bosker, R. J. (2011). Multilevel analysis: An introduction to basic and advanced multilevel modeling. Sage.

Stevens, P. A. J., \& Dworkin, A. G. (2019). The Palgrave handbook of race and ethnic inequalities in education. In P. A. J. Stevens, A. G. Dworkin (Ed.), The palgrave handbook of race and ethnic inequalities in education (Second). https://doi.org/10.1057/9781137317803

Stevens, P. A. J. (2009). Pupils' perspectives on racism and differential treatment by teachers: On stragglers, the ill and being deviant. British Educational Research Journal, 35(3), 413-430. https://doi. org/10.1080/01411920802044420 
Thijs, J., \& Verkuyten, M. (2014). School ethnic diversity and students' interethnic relations. British Journal of Educational Psychology, 84(1), 1-21. https://doi.org/10.1111/bjep.12032

Thomas, W., \& Thomas, D. S. (1928). The methodology of behavior study. The child in America: Behavior Problems and Programs, 553-576.

Timmerman, C., Vanderwaeren, E., \& Crul, M. (2003). The second generation in Belgium. International Migration Review, 37(4), 1065-1090. https://doi.org/10.1111/j.1747-7379.2003.tb00170.x

Todd, A. R., \& Galinsky, A. D. (2012). The reciprocal link between multiculturalism and perspectivetaking: How ideological and self-regulatory approaches to managing diversity reinforce each other. Journal of Experimental Social Psychology, 6, 1394-1398. https://doi.org/10.1016/j.jesp.2012.07. 007

Urbiola, A., Willis, G. B., Ruiz-Romero, J., Moya, M., \& Esses, V. (2017). Valuing diversity in Spain and Canada: The role of multicultural ideology in intergroup attitudes and intentions to reduce inequalities. International Journal of Intercultural Relations, 56, 25-38. https://doi.org/10.1016/j.ijintrel. 2016.10.006

Valiente, C., Swanson, J., DeLay, D., Fraser, A. M., \& Parker, J. H. (2020). Emotion-related socialization in the classroom: Considering the roles of teachers peers and the classroom context. Developmental Psychology, 56(3), 578-594. https://doi.org/10.1037/dev0000863.

Van Houtte, M. (2004). Tracking effects on school achievement: A quantitative explanation in terms of the academic culture of school staff. American Journal of Education, 110(4), 354-388. https://doi. org/10.1086/422790

Van Maele, D., \& Van Houtte, M. (2011). Collegial trust and the organizational context of the teacher workplace: The role of a homogeneous teachability culture. American Journal of Education, 117(4), 437-464. https://doi.org/10.1086/660754

Van Praag, L., Boone, S., Stevens, P. A. J., \& Van Houte, M. (2015). How tracking structures attitudes towards ethnic out-groups and interethnic interactions in the classroom: An ethnographic study in Belgium. Social Psychology of Education, 18, 165-184. https://doi.org/10.1007/s11218-014-9273-7

Verkuyten, M., \& Thijs, J. (2002a). Multiculturalism among minority and majority adolescents in the Netherlands. International Journal of Intercultural Relations, 26(1), 91-108. https://doi.org/10. 1016/S0147-1767(01)00039-6

Verkuyten, M., \& Thijs, J. (2002b). Racist victimization among children in The Netherlands: The effect of ethnic group and school. Ethnic and Racial Studies, 25(2), 310-331. https://doi.org/10.1080/ 0141987012010950

Verkuyten, M., \& Thijs, J. (2013). Multicultural education and inter-ethnic attitudes. European Psychologist. https://doi.org/10.1027/1016-9040/a000152

Vervaet, R., Van Houtte, M., \& Stevens, P. A. J. (2018b). The ethnic prejudice of flemish pupils: The role of pupils' and teachers' perceptions of multicultural teacher culture. Teachers College Record., $120(5)$, n5.

Vervaet, R., Van Houtte, M., \& Stevens, P. A. J. (2018a). Multicultural school leadership, multicultural teacher culture and the ethnic prejudice of Flemish pupils. Teaching and Teacher Education, 76, 68-77. https://doi.org/10.1016/j.tate.2018.08.009

Vervoort, M. H. M., Scholte, R. H. J., \& Overbeek, G. (2010). Bullying and victimization among adolescents: The role of ethnicity and ethnic composition of school class. Journal of Youth and Adolescence, 39, 1-11. https://doi.org/10.1007/s10964-008-9355-y

Williams, D. R., Lawrence, J. A., \& Davis, B. A. (2019). Racism and health: Evidence and needed research. Annual Review of Public Health, 40(1), 105-125. https://doi.org/10.1146/annurev-publh ealth-040218-043750

Wilton, L. S., Good, J. J., Moss-Racusin, C. A., \& Sanchez, D. T. (2015). Communicating more than diversity: The effect of institutional diversity statements on expectations and performance as a function of race and gender. Cultural Diversity and Ethnic Minority Psychology. https://doi.org/10.1037/ a0037883

Wong, C. A., Eccles, J. S., \& Sameroff, A. (2003). The influence of ethnic discrimination and ethnic identification on african american adolescents' school and socioemotional adjustment. Journal of Personality, 71(6), 1197-1232. https://doi.org/10.1111/1467-6494.7106012

Zembylas, M., \& Iasonos, S. (2010). Leadership styles and multicultural education approaches: An exploration of their relationship. International Journal of Leadership in Education, 13(2), 163-183. https://doi.org/10.1080/13603120903386969 
Publisher's Note Springer Nature remains neutral with regard to jurisdictional claims in published maps and institutional affiliations.

Fanny D'hondt Ph.D sociology, is post-doctoral researcher at the Department of Sociology, Ghent University and member of the research group CuDOS and CESSMIR. Her research focuses on ethnic discrimination, ethnic inequality and sociology of education.

Charlotte Maene is doctoral researcher at the Department of Sociology, Ghent University and member of the research group CuDOS and CESSMIR. Her research focuses on ethnic inequality in secondary education, collective identity of adolescents and prejudice.

Roselien Vervaet obtained her Ph.D in sociology at the Department of Sociology, Ghent University. Her core research interest is the determinants of ethnic prejudice among teachers and students in secondary education.

Mieke Van Houtte Ph.D sociology, is full professor and head of the CuDOS research team at the Department of Sociology at Ghent University (Belgium). Her research interests cover diverse topics within the sociology of education, particularly the effects of structural and compositional school features on several outcomes for students and teachers. She is a member of the Royal Flemish Academy of Belgium for Science and the Arts.

Peter A. J. Stevens is Associate Professor at the Department of Sociology, Ghent University and member of the research groups CuDOS and CESSMIR. His main fields of interest are race and ethnic relations, sociology of education and qualitative research. 